\title{
Passage Through a Small Drainage Culvert by Mule Deer, Odocoilus hemionus, and Other Mammals
}

\author{
Alissa Krawchuk ${ }^{1}$, Karl W. Larsen ${ }^{1}$, Richard D. Weir ${ }^{2}$, ANd Helen Davis ${ }^{2}$ \\ ${ }^{1}$ Department of Natural Resource Sciences, Thompson Rivers University, PO Box 3010, Kamloops, British Columbia V2C 5N3 \\ Canada \\ ${ }^{2}$ Artemis Wildlife Consultants, 4515 Hullcar Road, Armstrong, British Columbia V0E 1B4 Canada
}

Krawchuk, Alissa, Karl W. Larsen, Richard D. Weir, and Helen Davis. 2005. Passage through a small drainage culvert by Mule Deer, Odocoilus hemionus, and other mammals. Canadian Field-Naturalist 119(2): 296-298.

Cameras with infra-red triggers were used to monitor the passage of wildlife through underground passages that ran under a major highway and railway. Several species of mammals were detected traveling through the passages; of particular interest was the movement of Mule Deer (Odocoileus hemionus) through a relatively small culvert that would not have been predicted to see usage by these animals.

Key Words: road crossing, Mule Deer, Odocoilus hemionus, Black Bear, Ursus americanus, road ecology, underpass, highway crossing.

Numerous types of crossing structures exist to aid in the movement of wildlife across highways and railways. Some of these structures, such as drainage culverts, cattle underpasses and human underpasses, are not specifically designed for use by wildlife, yet they are ubiquitous features associated with highways, and are far more common than underpasses and overpasses specifically designed for wildlife. To this end, their potential and realized roles in reducing negative road effects on wildlife need to be explored. Culverts, for example, are known to be used by numerous types of wildlife including small mammals, reptiles, amphibians and large carnivores (Yanes et al. 1995; Rodriguez et al. 1996; Clevenger et al. 2001).

Interest in the ability of crossing structures to lower deer mortality on highways grew in the 1970s in response to large numbers of these animals being struck by vehicles in the United States (Puglisi et al. 1974; Allen and Cullough 1976). In particular, Reed et al. $(1975,1979)$ studied the use of underpasses by Mule Deer, Odocoilus hemionus, and as a result, the suitability of crossing structures for deer was well documented. Reed et al. $(1975,1979)$ identified the openness ratio (width*height/length) of these structures as an important factor influencing deer use. Their work suggested that structures with openness ratios of less than 0.6 would not be utilized by deer. This minimum guideline is somewhat difficult to test, as structures monitored for wildlife passage often are much larger (Yanes et al. 1995; Foster and Humphry 1995). One recent study that examined small crossings found that deer would use culverts as small as $4.2 \mathrm{~m}$ wide, $3.5 \mathrm{~m}$ tall, and $96.1 \mathrm{~m}$ long (openness ratio of 0.15 , Clevenger and Waltho 2000). In the same study, deer also were found to use underpasses as large as $14.9 \mathrm{~m}$ wide, $3.2 \mathrm{~m}$ tall and $38.0 \mathrm{~m}$ long (openness ratio of 1.25 ).

We conducted a small, localized study to document whether or not wildlife was using various passages under major transportation corridors in the region surrounding Kamloops, British Columbia. Herein we re- port on our results, particularly the repeated use of an unusually small culvert by deer.

\section{Methods}

This study took place in the fall of 2003. We chose three crossing structures (two drainage culverts and one cattle underpass) east of Kamloops, British Columbia $\left(119^{\circ} 52^{\prime} \mathrm{W}, 50^{\circ} 39^{\prime} \mathrm{N}\right)$ to monitor with infra-red sensor cameras. Each of these three crossings extends under both the Trans-Canada Highway and the Canadian Pacific Railway. The former is the major transportation corridor for motorists traveling through the Kamloops region. Monthly average daily traffic on this road for September to November ranges between 10000 and 15000 vehicles per day (British Columbia Ministry of Transportation, Transportation Information Management System data [1997-1999]). At two of the three sites we monitored (Site 1 and 2), the highway consisted of four lanes for at least $1 \mathrm{~km}$ in either direction. The dimensions of the crossing structures at the three sites are summarized in Table 1 (see Figure 1).

We used camera units (MacHutchon et al. 1998) constructed from $35 \mathrm{~mm}$ cameras with autofocus, wide angle lens, autoflash and date/time function (Olympus Af-1 Twin, Japan). These units were linked to passive infra-red sensors (Sureshot 6257-SPDT, Sentrol, USA) and hooked through a converter and an on/off switch to a 12 volt battery. The sensors were sensitive enough to be triggered by very small movements such as a breeze gently moving plants or a small animal passing by, if the movement was close enough to the camera (within $20 \mathrm{~m}$ ). The entire assembly was housed in a modified ammunition box that had been painted black.

The camera boxes were attached to right-angle brackets that allowed mounting on trees or fenceposts. The boxes also could be anchored directly to the ground, in situations where suitable mounting support was unavailable. Due to site characteristics and a limited availability of mounting structures, it was not always possible to position the cameras directly facing the 
TABLE 1. Crossing occurrence of wildlife in culverts, as detected by infra-red sensors and cameras near Kamloops, British Columbia, autumn 2003.

\begin{tabular}{lcccccc}
\hline \hline Location & $\begin{array}{c}\text { Passage } \\
\text { Width } \\
(\mathrm{m})\end{array}$ & $\begin{array}{c}\text { Passage } \\
\text { Height } \\
(\mathrm{m})\end{array}$ & $\begin{array}{c}\text { Passage } \\
\text { Length } \\
(\mathrm{m})\end{array}$ & $\begin{array}{c}\text { Openess Ratio } \\
(\text { width*height } \\
\text { /length) }\end{array}$ & Species detected & $\begin{array}{c}\text { Number of } \\
\text { detected } \\
\text { crossings }\end{array}$ \\
\hline Site 1* & 2.1 & 1.5 & 30 & 0.11 & $\begin{array}{l}\text { Black Bear } \\
\text { Mule Deer }\end{array}$ & $\begin{array}{c}\text { Black Bear } \\
\text { Raccoon } \\
\text { Site 2** }\end{array}$ \\
Site 3*** & 7.0 & 5.0 & 40 & 0.88 & none detected & 4 \\
\hline
\end{tabular}

* camera operational August 21 to November 13, 2003 (Figure 1)

** camera operational August 30 to November 13, 2003

*** camera operational September 5 to November 13, 2003

culverts. We also tried to position the cameras so that the flash would not go off directly in the eyes of any wildlife using the structure, thereby startling them and possibly discouraging use.

We visited each site and its camera station every few days, depending on the frequency of pictures taken and the battery strength. A spare battery allowed for rotation between the three cameras with minimal camera downtime. At each camera check, the battery strength and the number of exposures were noted. The presence of animal tracks or sign around the camera station also was noted, to confirm that the cameras were not miss- ing animals. From the developed photos, we counted the number of animals of each species detected at each camera. When the same animal was seen in a sequence of photos, it was only counted as one crossing event.

\section{Results}

Despite the brevity of the study and the small number of locations monitored, we were successful at detecting use of the crossing structures at two of three camera sites. Table 1 summarizes the native species documented using the crossing structures. Non-wildlife use detected by the cameras included humans, cattle

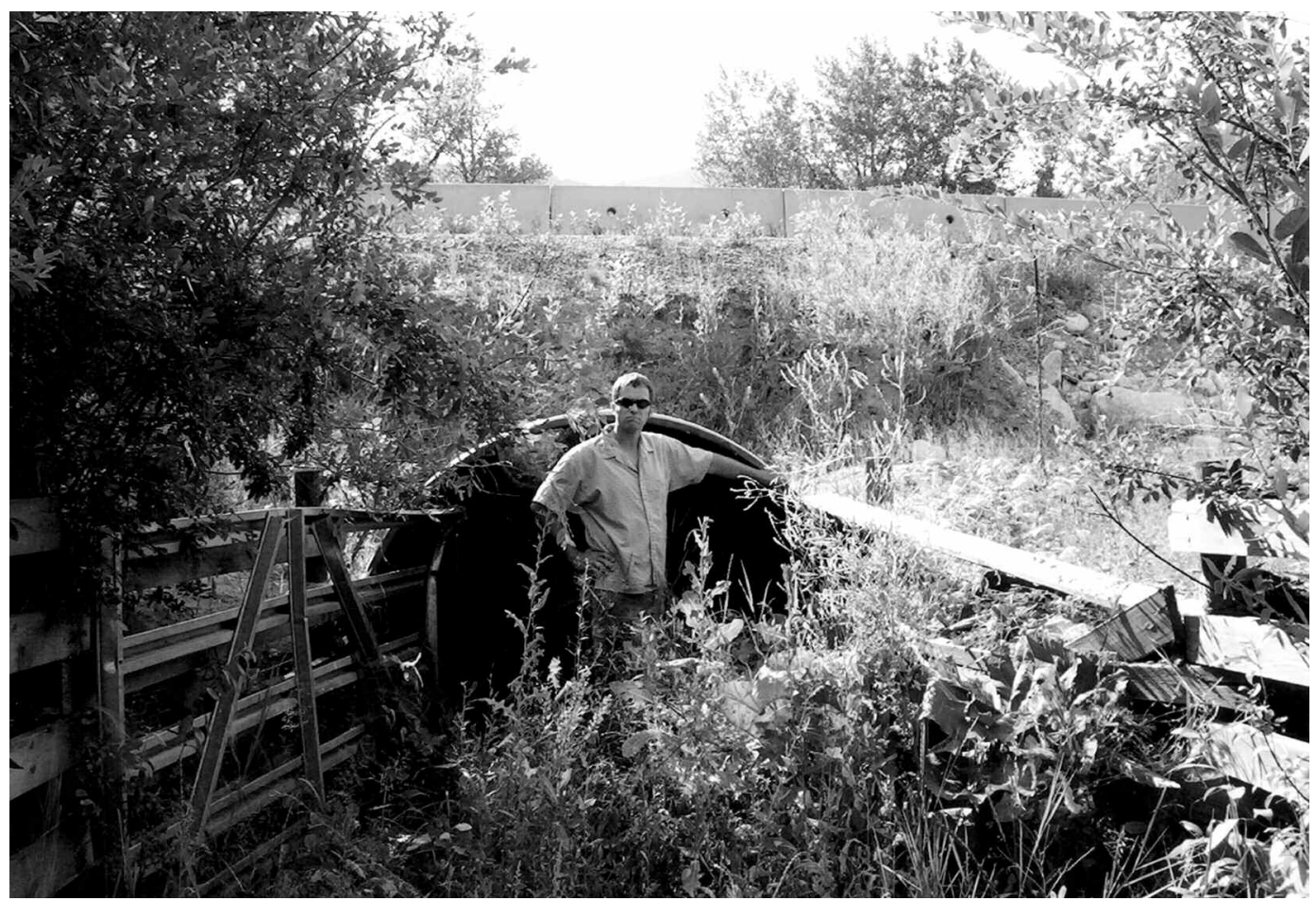

FIGURE 1. Drainage culvert at Site 1, used repeatedly by Mule Deer to travel under the Trans-Canada Highway near Kamloops, British Columbia (dimensions of culvert: $2.1 \mathrm{~m}$ wide, $1.5 \mathrm{~m}$ tall, $30 \mathrm{~m}$ long). 
and housecats. No photo of wildlife crossing was obtained at Site 3; however, a faulty flash mechanism on the camera at this site rendered all night-time photos indecipherable, so we simply may have failed to detect animals using this culvert for passage.

Mule Deer were detected traveling through the Site 1 culvert that had an openness ratio of only 0.11 (Table 1). The camera at this site recorded Mule Deer on six different occasions over the 10 -week study. This culvert had a dirt substrate, was surrounded on either side by vegetation, and was relatively far from human activity. Deer were not detected at Site 2, however, a road-killed deer was found within $50 \mathrm{~m}$ of the culvert during the study period, suggesting deer were in the vicinity. Deer also were not detected at Site 3, possibly due in part to the faulty flash (see above), but deer tracks were seen in the area of the underpass during the study period.

\section{Discussion}

Our general observations of Black Bear, Ursus Americanus, Raccoon, Procyon lotor, and Mule Deer passing through the monitored culverts are in keeping with results from other studies (e.g., Clevenger and Waltho, 2000; LaPoint et al. 2003). However, of particular interest is the use of the drainage culvert at Site 1 by Mule Deer, as previous work has suggested that ungulates are reluctant to use structures less than $7 \mathrm{~m}$ wide or $2.4 \mathrm{~m}$ high, or with an openness ratio of less than 0.6 (Reed et al. 1975; Reed et al. 1979; Yanes et al. 1995). This is substantially greater than the ratio for the culvert at Site 1 in this study. However, Clevenger and Waltho (2000) recently reported on the use by deer of an underpass with an openness ratio of 0.15 in Banff, which together with our study supports the notion that deer may be more plastic in their use of crossing structures than previously thought.

Our failure to detect deer crossing at Sites 2 and 3 (even though evidence showed deer were in the area) likely is due in part to our small sampling period, and a host of other potential factors (Rodriguez et al. 1996, Clevenger et al. 2001). Unlike Site 1, the culverts at Site 2 and 3 lacked a large amount of surrounding natural vegetation, a feature found to increase the use of crossings by wildlife (Yanes et al. 1995). The natural dirt substrate on the bottom of the culvert at Site1 also may have encouraged its use by deer, as a substrate of soil and detritus has been reported to be less hostile to wildlife (Reed et al. 1975; Yanes et al. 1995). Further, it has been suggested that elevated noise levels associated with human activity deter wildlife from utilizing culverts close to such areas (Clevenger et al. 2000), and the Site 1 culvert, where deer were detected, was relatively far away from human activity.
Despite the limitations of our study, we documented the passage of Mule Deer under a major highway, through a culvert that would not have been predicted to show usage by these animals. Our observations suggest further research is required on the use or avoidance of culverts and other structures not specifically designed for wildlife.

\section{Acknowledgments}

The Smith family graciously allowed us to set up a monitoring camera on their property near Pritchard, British Columbia. Thanks to E. Lofroth and T. Hamilton for facilitating this project. This study was funded by the Habitat Conservation Trust Fund of British Columbia.

\section{Literature Cited}

Allen, R. E., and D. R. McCullough. 1976. Deer-car accidents in southern Michigan. Journal of Wildlife Management 40: 317-325.

Clevenger, A. P., and N. Waltho. 2000. Factors influencing the effectiveness of wildlife underpasses in Banff National Park, Alberta, Canada. Conservation Biology 14: 47-56.

Clevenger, A. P., B. Chruszcz, and K. Gunson. 2001. Drainage culverts as habitat linkages and factors affecting passage by mammals. Journal of Applied Ecology 38: 1340-1349.

Foster, M. L., and S. R. Humphry. 1995. Use of highway underpasses by Florida panthers and other wildlife. Wildlife Society Bulletin 23: 95-100.

LaPoint, S. D., R. W. Kays, and J. C. Ray. 2003. Animals crossing the Northway: are existing culverts useful? Adirondack Journal of Environmental Studies 10: 11-17.

MacHutchon, A. G., S. Himmer, H. Davis, and M. Gallagher. 1998. Temporal and spatial activity patterns among coastal bear populations. Ursus 10: 539-546.

Puglisi, M. J., J. S. Lindzey, and E. D. Bellis. 1974. Factors associated with highway mortality of white-tail deer. Journal of Wildlife Management. 38: 799-807.

Reed, D. F., T. N. Woodward, and T. M. Pojar. 1975. Behavioural response of Mule deer to a highway underpass. Journal of Wildlife Management 39: 361-367.

Reed, D. F., T. N. Woodward, and T. D. I. Beck. 1979. Regional deer-vehicle accident research. U.S. Department of Transport Federal Highway Adminstration Report FHWA-RD-79-11. National Technical Information Service, Springfield, Virginia. 61 pages.

Rodriguez, A., G. Crema, and M. Delibes. 1996. Use of non-wildlife passages across a high speed railway by terrestrial vertebrates. Journal of Applied Ecology 33: 15271540.

Yanes, M., J. M.Velasco, and F. Suarez. 1995. Permeability of roads and railways to vertebrates: the importance of culverts. Biological Conservation 71: 217-222.

Received 27 September 2004

Accepted 6 February 2005 